\title{
A Hospital based cross sectional study to find out factors associated with disease severity and length of hospital stay in COVID-19 patients in Tertiary Care Hospital of Ahmedabad city
}

Arpit Chelabhai Prajapati ${ }^{1}$, Mansi Maulik Patel ${ }^{2}$, Hardika Jamanadas Khanpara ${ }^{3}$, Rujul Pankajbhai Shukla ${ }^{4}$, Donald Shailendra Christian ${ }^{5}$, Ashaben kacharabhai solanki ${ }^{6}$, Disha Rajeshbhai Geriya ${ }^{7}$

${ }^{1}$ Associate Professor, GCS Medical College, Hospital \& Research Centre, Ahmedabad, Gujarat; ${ }^{2}$ Assistant Professor, GCS Medical College, Hospital \& Research Centre, Ahmedabad, Gujarat; ${ }^{3}$ Assistant Professor, GCS Medical College, Hospital \& Research Centre, Ahmedabad, Gujarat; ${ }^{4}$ Assistant Professor, GCS Medical College, Hospital \& Research Centre, Ahmedabad, Gujarat; ${ }^{5}$ Associate Professor, GCS Medical College, Hospital \& Research Centre, Ahmedabad, Gujarat; ${ }^{6} 3$ rd Year Post graduate Student, GCS Medical College, Hospital \& Research Centre, Ahmedabad, Gujarat; ${ }^{7}$ 2nd Year Post graduate Student, GCS Medical College, Hospital \& Research Centre, Ahmedabad, Gujarat

\begin{tabular}{|c|c|c|c|c|c|c|c|c|}
\hline Abstract & Introduction & Methodology & Results & Conclusion & $\underline{\text { References }}$ & Citation & \multicolumn{2}{|c|}{ Tables / Figures } \\
\hline \multicolumn{9}{|c|}{ Corresponding Author } \\
\hline \multicolumn{8}{|c|}{$\begin{array}{l}\text { Dr Arpit C. Prajapati, 22, Sapphire Bungalow, Near Coral Bungalows, Opp. Anmol apartment, Nana Chiloda, } \\
\text { Ahmedabad, Gujarat - } 382330 \\
\text { E Mail ID: doc.arpitprajapati@gmail.com }\end{array}$} & 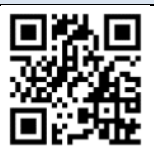 \\
\hline
\end{tabular}

\section{Citation}

Prajapati AC, Patel MM, Khanpara HJ, Shukla RP, Christian DS, Solanki AK, Geriya DR. A Hospital based cross sectional study to find out factors associated with disease severity and length of hospital stay in COVID-19 patients in Tertiary Care Hospital of Ahmedabad city. Indian J Comm Health. 2021;33(2):256-259. https://doi.org/10.47203/IJCH.2021.v33i02.006

Source of Funding: Nil Conflict of Interest: None declared

\section{Article Cycle}

Received: 06/04/2021; Revision: 05/05/2021; Accepted:28/05/2021; Published:30/06/2021

This work is licensed under a Creative Commons Attribution 4.0 International License.

\section{Abstract}

Background: Tertiary hospital care may vary from isolation bed ward care to high dependency units (HDUs) with oxygen support to intensive care unit (ICU) where patients may be intubated for mechanical ventilation The major risk factors for severe disease are age more than 60 years and underlying diseases like diabetes, hypertension. COVID-19 patients present at varying levels of severity. Understanding how long patients hospitalized with COVID-19 remain in hospital is critical for planning. Objectives: 1 . To determine risk factors associated with disease severity 2 . To determine risk factors associated with length of hospital stay in COVID-19 patients 3. To study the disease outcome Material \& Methods: This was retrospective record-based study of inpatients with COVID-19 at Tertiary Care Hospital of Ahmedabad City. All patients admitted at tertiary care hospital diagnosed with COVID-19 between April 2020 to June, 2020, were included in present study. Inclusion criteria were all COVID-19 patients admitted at tertiary care hospital during the duration of April 2020 to June 2020. Results: A total of 916 COVID-19 patients were included in the study. Out of 916 total admitted patients $526(57.4 \%)$ were male. 174 (19\%) patients having one or more comorbidities like diabetes, hypertension, tuberculosis, heart diseases etc. Total 769 discharged (83.9\%), 115 deaths (12.6\%) and 32 transferred to other COVID-19 hospital (3.5\%) out of total 916 patients admitted during study period. Conclusion: Severity of disease and deaths were associated with age and comorbidities. COVID-19 patients with comorbidities have more deteriorating outcomes compared with patients without.

\section{Keywords}

COVID-19; Disease Severity; Length of Stay; Outcome

\section{Introduction}

COVID-19 disease caused by SARS-CoV-2. Coronavirus is relatively a newer disease, with fresh information being known on a dynamic basis about the natural history of the disease.(1) Currently $80 \%$ of the patients infected with COVID-19 are experiencing mild or moderate symptoms.(2)
The most common initial symptoms of Covid-19 are cough, fever, fatigue. Severe COVID-19 illness begins around 1 week after the onset of symptoms.

Confirmed case of SARS-CoV-2 infection is either person with a positive Nucleic Acid Amplification Test (NAAT) or person with a positive SARS-CoV-2 Antigen-Rapid Diagnostic Test and meeting either the probable case 
definition or suspect criteria or an asymptomatic person with a positive SARS-CoV-2 Antigen-RDT who is a contact of a probable or confirmed case. (3)

Most people with COVID-19 experience mild symptoms. Around $10-15 \%$ of COVID-19 cases develop to severe disease, and of them $5 \%$ become critically ill. Typically COVID-19 patients improve after within 6 weeks of illness.(4)

Severe or critical illness from COVID-19 is clearly defined as hospitalization, admission to the ICU, intubation or mechanical ventilation, or death. (5) The considerable risk factors for severe disease are age more than 60 years and underlying non-communicable diseases (NCDs) like diabetes mellitus, hypertension.(6)

COVID-19 patients present at varying levels of severity. Understanding how long patients hospitalized with COVID-19 remain in hospital is critical for planning. This review found that hospital Length of Stay (LoS) observations for COVID-19 patients published in the literature to date varied from less than a week to nearly 2 months. $(7,8,9)$

\section{Aims \& Objectives}

1. To determine risk factors associated with disease severity

2. To estimate of the duration and risk factors associated with hospitalization of COVID-19 patients

\section{Material \& Methods}

This was retrospective record-based study of inpatients with COVID-19 at Tertiary Care Hospital of Ahmedabad City. All patients admitted at tertiary care hospital diagnosed with COVID-19 between April to June, 2020, were included in present study. Inclusion criteria were all COVID-19 inpatients (RT-PCR positive or Antigen Test Positive) admitted at GCS Medical College, Hospital \& Research Centre during the April to June 2020.

All statistical analyses were conducted in MS Excel and Epi info version 7.2. Percentage, Median, Chi-square test were calculated in the study. Ethical committee approval was taken from the institution \& Clinical Trial registration number for trial is CTRI/2020/07/026955.

\section{Results}

As shown in (Table 1), A total of 916 COVID-19 patients were included in the present study admitted during April 2020 to June 2020. Out of 916 total admitted patients 526 $(57.4 \%)$ were male while $390(42.6 \%)$ were female. Amongst total 916 COVID-19 patients 680 (74.2\%) were vegetarian. As shown in (Figure 1), Total 769 discharged (83.9\%), 115 deaths (12.6\%) and 32 transferred to other COVID-19 hospital (3.5\%) out of total 916 patients admitted during study period. (Table 2) shows that 174 (19\%) patients having one or more comorbidities like diabetes, hypertension, tuberculosis, heart diseases etc. As depicted in (Table 1) \& (Table 2), severity of deaths were associated with age and comorbidity.
In this study, median length of stay of covid-19 hospitalization was 6 days. Median length of stay in hospital in isolation ward, in HDU ward, in ICU without Ventilator \& in ICU with ventilator was 5 days, 3 days, 1 day and 3 days. As depicted in [Table 3], Median length of stay in hospital was more as age increasing. Length of stay in hospital was more in female and who have comorbidity like hypertension, diabetes mellitus, coronary heart disease, cerebrovascular disease, cancer, Chronic Obstructive Pulmonary Disease (COPD). Total 797 covid19 patients $(87 \%)$ in isolation ward while 561 patients (61.3\%) were required admission in High Dependency Unit (HDU) ward, 123 patients (13.4\%) had required ICU care and 105 patients $(11.5 \%)$ had required ICU care with ventilatory support.

Out of 916 COVID-19 patients, 174 patients (19\%) were having one or more comorbidity like Hypertension, Diabetes Mellitus, Renal Diseases, Coronary Heart Disease, Chronic Obstructive Pulmonary Disease (COPD), Cerebrovascular Disease, Cancer etc. Severity of COVID-19 infection and deaths were associated with age and comorbidities. COVID-19 Patients with comorbidity has the worst prognosis. ( $p$ value $<0.00001$ ).

\section{Discussion}

In the current study, total $84 \%$ were recovered from illness while in similar other study out of 730 COVID-19 patients, $92.5 \%$ recovered and $7.5 \%$ were considered to be patient died or was discharged against medical advice (DAMA). The median length of hospital stay of COVID-19 patients was found to be 7 days(10) while in the current study median length of hospital stay of COVID-19 patients was 6 days.

In other similar studies, all deaths occurred among patients with critical illness, and the overall case fatality rate (CFR) was $2.3 \%$.(11) The CFR among patients with severe disease was 49\%.(11) Among children in China, illness severity was lower than in adults, with $94 \%$ of affected children having asymptomatic, mild, or moderate disease; $5 \%$ having severe disease; and less than $1 \%$ having critical disease.(12) Among U.S. COVID-19 cases reported January - May, 2020, overall the proportion of people who were hospitalized was $14 \%$, including $2 \%$ admitted to the intensive care unit (ICU). Over all $5 \%$ of patients died.(13) A systematic review of early evidence on length of stay, Median hospital length of stay (LoS) ranged from 4 to 53 days within China, and 4 to 21 days outside of China, across 45 studies.(14)

In study conducted at other region showed male seniors, especially among those aged $\geq 70$ years, are being disproportionately affected by the pandemic. (15) In other studies also showed Covid-19 disease with co-morbidities significantly affect the prognosis and severity of COVID$19 .(16,17)$ In the present study total 115 deaths $(12.6 \%)$ occurred out of which 77 were male (67\%). Evidence from 
China and Europe has also suggested that mortality from COVID-19 infection is higher in men than women.(18)

As shown in (Table 1), age is the important factor for death or severe illness, and the risk increases with each additional decade. Patients having chronic disease such as cardiovascular disease, diabetes mellitus, immunosuppression, and obesity are more likely to become critically ill from COVID-19. Severe disease is more common among men than among women.(19) Hypertension (22.4\%) and diabetes (10.3\%) were the most common comorbidities reported by the patients.(20) Most people with COVID-19 recover; however, people with chronic diseases are also at higher risk of death if they become infected. (21)

In another study, the median age was 67 years (interquartile range 56-78), a majority had one or more comorbidity, $12 \%$ required mechanical ventilation within $24 \mathrm{~h}$, median LOS was 7 (3-14) days, and in-hospital 28day mortality was $26 \%$.(22) The median age of the patients was 48 years (IQR 35-62) and the median LOS was 18 days (IQR 13-25). (23)

COVID-19 Patients with comorbidity has higher deaths (24.9\%) as compared to patients having no comorbidity $(10.2 \%)$ ( $p$ value $<0.00001$ ), while in similar study conducted in china, disease severity was associated with age $(P<0.001)$, comorbidities $(P<0.001)$ significantly. (24)

\section{Conclusion}

Severity of COVID-19 infection and deaths were associated with age and comorbidities. Patients with comorbidity has the worst prognosis. COVID-19 patients with comorbidities have more deteriorating outcomes compared with patients without. Median length of stay in hospital was more in older age, among female and patients having comorbidity

\section{Recommendation}

Length of stay distributions can be used to model bed demands for contingency planning and preparedness by health department. Identified associated factors can be modified to improve the outcomes of patients with COVID-19.

\section{Limitation of the study}

All COVID-19 patients (study participants) were selected from one tertiary care center of Ahmedabad city

\section{Relevance of the study}

Current study adds supporting evidence to factors associated with the disease severity and increased length of stay.

\section{Authors Contribution}

All author contributed equally.

\section{Acknowledgement}

Authors would like to thank Dr. Kirti Patel (Director, GCSMCH\&RC) Dr. Yogendra Modi (Dean, GCSMCH\&RC)
Dr. Sunil Rao (CEO, GCSMCH\&RC), Dr. Naimish Patel (Professor, General Medicine), Dr.Heena Chhanwal (Professor \& Head, Anesthesiology) for their valuable suggestions and support.

\section{References}

1. Post COVID Management Protocol Background.; 2020.

2. COVID-19 advice - Know the facts | WHO Western Pacific. Accessed March 13, 2021. https://www.who.int/westernpacific/emergencies/covid19/information/severity

3. WHO-2019-nCoV-Surveillance_Case_Definition-2020.2-eng.

4. Tenforde MW, Kim SS, Lindsell CJ, et al. Symptom Duration and Risk Factors for Delayed Return to Usual Health Among Outpatients with COVID-19 in a Multistate Health Care Systems Network United States, March-June 2020. MMWR Morbidity and Mortality Weekly Report. 2020;69(30):993-998. doi:10.15585/mmwr.mm6930e1

5. Americans $L$. Being a current or former cigarette smoker increases the risk for severe illness from COVID-19. 1 Non-Hispanic American Indians and Alaska Natives $O$ People of multiple races Both smoking and COVID-19 disproportionately impact racial, ethnic, and sexual minority groups. 5,6. doi:10.15585/mmwr.mm6924e2

6. (No Title). Accessed March 16, 2021 https://www.mohfw.gov.in/pdf/UpdatedClinicalManagementProt ocolforCOVID19dated03072020.pdf

7. Jiang F, Deng L, Zhang L, Cai Y, Cheung CW, Xia Z. Review of the Clinical Characteristics of Coronavirus Disease 2019 (COVID-19). Journal of General Internal Medicine. 2020;35(5):1545-1549. doi:10.1007/s11606-020-05762-w

8. Cascella M, Rajnik M, Cuomo A, Dulebohn SC, di Napoli R. Features, Evaluation and Treatment Coronavirus (COVID-19). StatPearls Publishing; 2020. Accessed March 17, 2021. http://www.ncbi.nlm.nih.gov/pubmed/32150360

9. Rodriguez-Morales AJ, Cardona-Ospina JA, Gutiérrez-Ocampo E, et al. Clinical, laboratory and imaging features of COVID-19: A systematic review and meta-analysis. Travel Medicine and Infectious Disease. 2020;34:101623. doi:10.1016/j.tmaid.2020.101623

10. Thiruvengadam G, Lakshmi M, Ramanujam R. A Study of Factors Affecting the Length of Hospital Stay of COVID-19 Patients by CoxProportional Hazard Model in a South Indian Tertiary Care Hospital. Journal of Primary Care \& Community Health. 2021;12:215013272110002. doi:10.1177/21501327211000231

11. Wu Z, McGoogan JM. Characteristics of and Important Lessons from the Coronavirus Disease 2019 (COVID-19) Outbreak in China: Summary of a Report of 72314 Cases from the Chinese Center for Disease Control and Prevention. JAMA - Journal of the American Medical Association. 2020;323(13):1239-1242. doi:10.1001/jama.2020.2648

12. Dong $Y$, Dong $Y$, Mo X, et al. Epidemiology of COVID-19 among children in China. Pediatrics. 2020;145(6). doi:10.1542/peds.20200702

13. Stokes EK, Zambrano LD, Anderson KN, et al. Coronavirus Disease 2019 Case Surveillance - United States, January 22-May 30, 2020. MMWR Morbidity and Mortality Weekly Report. 2020;69(24):759765. doi:10.15585/mmwr.mm6924e2

14. Rees EM, Nightingale ES, Jafari Y, et al. COVID-19 length of hospital stay: A systematic review and data synthesis. BMC Medicine. 2020;18(1):270. doi:10.1186/s12916-020-01726-3

15. Undurraga EA, Chowell G, Mizumoto K. COVID-19 case fatality risk by age and gender in a high testing setting in Latin America: Chile, March-August 2020. Infectious Diseases of Poverty. 2021;10(1):11. doi:10.1186/s40249-020-00785-1

16. Biswas $M$, Rahaman S, Biswas TK, Haque Z, Ibrahim B. Association of Sex, Age, and Comorbidities with Mortality in COVID-19 Patients: A Systematic Review and Meta-Analysis. Intervirology. 2021;64(1):36-47. doi:10.1159/000512592 
INDIAN JOURNAL OF COMMUNITY HEALTH / VOL 33 / ISSUE NO 02 / APR-JUN2021

17. Barek MA, Aziz MA, Islam MS. Impact of age, sex, comorbidities and clinical symptoms on the severity of COVID-19 cases: A metaanalysis with 55 studies and 10014 cases. Heliyon. 2020;6(12):e05684. doi:10.1016/j.heliyon.2020.e05684

18. Vahidy FS, Pan AP, Ahnstedt $H$, et al. Sex differences in susceptibility, severity, and outcomes of coronavirus disease 2019: Cross-sectional analysis from a diverse US metropolitan area. Lazzeri C, ed. PLOS ONE. 2021;16(1):e0245556. doi:10.1371/journal.pone.0245556

19. Berlin DA, Gulick RM, Martinez FJ. Severe Covid-19. Solomon CG, ed. New England Journal of Medicine. 2020;383(25):2451-2460. doi:10.1056/NEJMcp2009575

20. Wu S, Xue L, Legido-Quigley $\mathrm{H}$, et al. Understanding factors influencing the length of hospital stay among non-severe COVID-19 patients: A retrospective cohort study in a Fangcang shelter
[Tertiary Care Hospital...] | Prajapati AC et al hospital. Serra R, ed. PLOS ONE. 2020;15(10):e0240959. doi:10.1371/journal.pone.0240959

21. Vulnerable populations. Accessed April 3, 2021 http://www.bccdc.ca/health-professionals/clinicalresources/covid-19-care/clinical-care/vulnerable-populations

22. Anderson MR, Bach PB, Baldwin MR. Hospital Length of Stay for Patients with Severe COVID-19: Implications for Remdesivir's Value. 2021;5:129-131. doi:10.1007/s41669-020-00243-6

23. Chen F-J, Li F-R, Zheng J-Z, et al. Factors associated with duration of hospital stay and complications in patients with COVID-19. Journal of Public Health and Emergency. 2021;5(0):6-6. doi:10.21037/jphe20-74

24. Wang D, Li R, Wang J, et al. Correlation analysis between disease severity and clinical and biochemical characteristics of 143 cases of COVID-19 in Wuhan, China: A descriptive study. BMC Infectious Diseases. 2020;20(1):519. doi:10.1186/s12879-020-05242-w

\section{Tables}

\section{TABLE 1 AGE WISE DISTRIBUTION OF THE COVID-19 PATIENTS}

\begin{tabular}{|c|c|c|c|c|c|}
\hline Sr. No. & Age group (in years) & Frequency (\%) & Male (\%) & Female (\%) & No. of Deaths (\%) \\
\hline 1 & $0-10$ & $06(0.7)$ & $02(33.3)$ & $04(66.7)$ & $0(0)$ \\
\hline 2 & $10-20$ & $19(2.1)$ & $08(42.1)$ & $11(57.9)$ & $0(0)$ \\
\hline 3 & $20-30$ & $121(13.2)$ & $34(28.1)$ & $87(71.9)$ & $1(0.8)$ \\
\hline 4 & $30-40$ & $149(16.3)$ & $90(60.4)$ & $59(39.6)$ & $4(2.7)$ \\
\hline 5 & $40-50$ & $163(17.8)$ & $113(69.3)$ & $50(30.7)$ & $11(6.8)$ \\
\hline 6 & $50-60$ & $221(24.1)$ & $125(56.6)$ & $96(43.4)$ & $47(21.3)$ \\
\hline 7 & $60-70$ & $163(17.8)$ & $100(61.3)$ & $63(38.7)$ & $31(19.0)$ \\
\hline 8 & $70-80$ & $62(6.8)$ & $47(75.8)$ & $15(24.2)$ & $16(25.8)$ \\
\hline 9 & $\geq 80$ & $12(1.3)$ & $07(58.3)$ & $05(41.7)$ & $5(41.7)$ \\
\hline \multicolumn{2}{|r|}{ Total } & 916 & 526 & 390 & 115 \\
\hline
\end{tabular}

\begin{tabular}{|c|c|c|c|c|}
\hline Comorbidity & Total discharged (\%) & No. of Deaths (\%) & Total (\%) & $\mathrm{X}^{2}$ test ( $p$ value) \\
\hline Present & $127(16.5)$ & $42(36.5)$ & 169 (19.1) & \multirow[t]{3}{*}{$25.89(<0.00001)$} \\
\hline Absent & $642(83.5)$ & $73(63.5)$ & 715 (80.9) & \\
\hline Total & 769 & 115 & 884 & \\
\hline
\end{tabular}

TABLE 3 AGE-WISE AND COMORBIDITY

DISTRIBUTION OF LENGTH OF STAY AT HOSPITAL

\begin{tabular}{|l|l|}
\hline \multicolumn{2}{|c|}{ Median days (length of stay in hospital) } \\
\hline Age group & 04 \\
\hline $\mathbf{0 - 2 0}$ & 06 \\
\hline $\mathbf{2 0 - 4 0}$ & 06 \\
\hline $\mathbf{4 0 - 6 0}$ & 07 \\
\hline $\mathbf{6 0 - 8 0}$ & 09 \\
\hline $\mathbf{8 0 - 1 0 0}$ & \\
\hline Sex & 06 \\
\hline Male & 07 \\
\hline Female & \\
\hline Comorbidity & 07 \\
\hline Present & 06 \\
\hline Absent & \\
\hline
\end{tabular}

\section{Figures}

FIGURE 1 OUTCOME OF COVID-19 ADMITTED PATIENTS

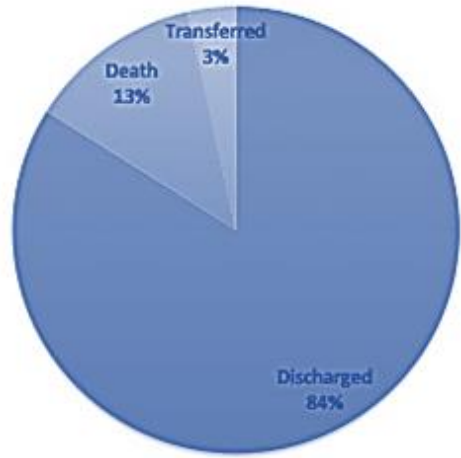

wischarged $\equiv$ Death aTransferred 